\title{
Endoscopic injection sclerosis: effective treatment for bleeding peptic ulcer
}

\author{
C Rajgopal, K R Palmer
}

\begin{abstract}
One hundred and nine patients presenting with severe haemorrhage from benign peptic ulcers were randomised to either endoscopic injection sclerotherapy using a combination of 1:100 000 adrenaline and $5 \%$ ethanolamine or to conservative treatment. Only high risk patients with active bleeding or endoscopic stigmata of recent haemorrhage and accessible ulcers were considered. The two groups were well matched for age, shock, haemoglobin concentration, endoscopic findings, and consumption of non-steroidal anti-inflammatory drugs. The group treated endoscopically had a significantly reduced rebleeding rate $(12 \cdot 5 \% v$ $47 \%, p<0 \cdot 001)$. Rebleeding was successfully treated in some patients by injection sclerotherapy, other patients underwent urgent surgery. While there was a tendency towards a lower operation rate and lower transfusion requirements in the treated group, this failed to achieve statistical significance. The use of injection sclerotherapy in the conservatively treated group after rebleeding undoubtedly reduced the number of surgical operations. Endoscopic injection sclerotherapy is effective in the prevention of rebleeding in these patients.
\end{abstract}

Bleeding peptic ulcer can be treated by a range of endoscopic techniques including $\mathrm{Nd}-\mathrm{Yag}$ laser photocoagulation, ${ }^{12}$ the heater probe, ${ }^{34}$ bipolar, ${ }^{56}$ or monopolar ${ }^{78}$ electrodes. These modalities tend to be expensive, require highly trained assistance and technical back up, and are not widely used. Recent attention has focused upon injection sclerotherapy of the bleeding area using adrenaline alone, ${ }^{9}$ a sclerosant alone, ${ }^{10}{ }^{11}$ or

TABLE I Demography of patients randomised to endoscopic injection sclerotherapy and conservative therapy

Gastroenterology Unit, Western General Hospital, Edinburgh C Rajgopal

K R Palmer

Correspondence to: Dr C Rajgopal Gastrointestinal Unit, Western General Hospital, Crewe Road, Edinburgh EH4 2XU.

Accepted for publication 30 August 1991 adrenaline combined with a sclerosant. ${ }^{12}{ }^{13}$ Trials of injection therapy have reported favourable results, although some have involved relatively small numbers of patients ${ }^{11}$ and others have been uncontrolled. ${ }^{112}$

We report the first British controlled trial of injection sclerotherapy for bleeding peptic ulcer, involving four acute admitting hospitals in a single centre. Only high risk patients with endoscopic stigmata of recent haemorrhage ${ }^{14}$ were included because the prognosis of patients without these factors is excellent.

\section{Methods}

DESIGN AND INCLUSION CRITERIA

Patients presenting with severe gastrointestinal haemorrhage defined by the admitting team were considered for the study. A history of smoking, alcohol consumption, and use of nonsteroidal anti-inflammatory drugs was obtained and evidence of cardiorespiratory and liver disease was sought. After hospital admission one of the authors (principally CR) was contacted and attended or performed upper gastrointestinal endoscopy which was completed within 24 hours of admission under diazepam or midazolam sedation using an Olympus XQ10 forward viewing gastroscope. Patients found to have a peptic ulcer that was either spurting blood at the time of endoscopy or had a non-bleeding protuberant vessel, adherent blood clot, or black spots (stigmata of recent haemorrhage) were entered into the study if they also had at least one other risk factor $^{1516}$ - age over 60 years, haemoglobin concentration less than $10 \mathrm{~g} / \mathrm{dl}$ at the time of presentation, or shock (defined as a pulse rate greater than 100 beats/minute or a systolic blood pressure less than $100 \mathrm{~mm} \mathrm{Hg}$, or both). Patients with known severe liver or renal disease, primary malignancy of the upper gastrointestinal tract,

\begin{tabular}{lll}
\hline & $\begin{array}{l}\text { Conservative } \\
\text { treatment } \\
(n=53)\end{array}$ & $\begin{array}{l}\text { Endoscopic } \\
\text { therapy } \\
(n=56)\end{array}$ \\
\hline Median (range) age (yrs) & $67(21-91)$ & $68(25-96)$ \\
$\begin{array}{l}\text { Mean (SD) admission haemoglobin } \\
\quad \text { concentration (g/d) }\end{array}$ & $9 \cdot 6(2 \cdot 4)$ & $8 \cdot 9(2 \cdot 3)$ \\
Shocked & 27 & 37 \\
Taking non-steroidal anti- & 18 & 22 \\
inflammatory drugs & 21 & 27 \\
Visible vessel & 5 & 4 \\
Spurting vessel & 13 & 11 \\
Cardiorespiratory disease & 23 & 20 \\
Gastric ulcer & 26 & 33 \\
Duodenal ulcer & 4 & 3 \\
Anastomotic ulcer & & \\
\hline
\end{tabular}

\begin{tabular}{lcl} 
TABLE II Clinical outcome of two groups of patients \\
\hline & $\begin{array}{l}\text { Conservative } \\
\text { treatment } \\
(n=53)\end{array}$ & $\begin{array}{l}\text { Endoscopic } \\
\text { therapy } \\
(n=56)\end{array}$ \\
\hline $\begin{array}{l}\text { Rebleeding episodes } \\
\begin{array}{l}\text { Median (range) transfusion } \\
\text { requirements (units) }\end{array}\end{array}$ & 25 & $7^{\star}$ \\
$\begin{array}{l}\text { Median (range) duration of hospital } \\
\text { admission (days) }\end{array}$ & $8(0-20)$ & $3(0-14)$ \\
$\begin{array}{l}\text { Operations } \\
\text { Deaths }\end{array}$ & 13 & $8(4-32)$ \\
\hline
\end{tabular}

${ }^{\star} \mathrm{p}<0.001$. 
extensive metastatic malignant disease, and those taking anticoagulant drugs were excluded.

If patients were suitable for the study, a sheathed variceal injection needle (Olympus NM3K) was positioned next to the ulcer and if the lesion was considered accessible to sclerotherapy, randomisation to either injection sclerotherapy or conservative treatment was performed by opening a sealed envelope.

ENDOSCOPIC TECHNIQUES

Patients randomised to the conservative treatment group did not receive endoscopic therapy and were managed conventionally.

Those randomised to injection sclerotherapy were treated by injection using a variceal injection needle of 1:100000 adrenaline and 5\% ethanolamine. Four injections of adrenaline each of 1-2 $\mathrm{ml}$ were first placed at the periphery of the ulcer; this causes mucosal swelling and blanching, and active bleeding almost invariably stops. Smaller injections of the sclerosant, up to a total of $0.5-1.5 \mathrm{ml}$, were then put either into the periphery of the lesion or for large visible vessels, into the bleeding point itself.

FOLLOW UP

Both actively and conservatively treated patients received treatment with an $\mathrm{H}_{2}$ receptor antagonist drug and were managed entirely by the admitting unit. Whenever possible, members of the unit were unaware of whether or not the patient had received injection sclerotherapy.

The following end points were determined:

(a) Rebleeding. This was defined as fresh haematemesis or melaena, or both, with either shock (pulse rate greater than 100 beats/minute, systolic blood pressure less than $100 \mathrm{mmHg}$ ) or a fall in haemoglobin concentration greater than 2 g/dl over a 24 hour period.

(b) Surgical operation. The decision to operate, like all other management decisions, was left entirely to the admitting clinicians. Continuing bleeding or rebleeding were the only indications for surgery. Operations performed were undersewing of duodenal ulcer with truncal vagotomy and pyloroplasty ( $n=9$ patients), excision of gastric ulcer $(n=5)$, partial gastrectomy $(n=3)$, undersewing of gastric ulcer with truncal vagotomy and gastroenterostomy $(n=1)$, and undersewing of gastric ulcer alone $(n=1)$.

(c) Number of units of blood transfused.

(d) Duration of hospital admission (days).

(e) Thirty day mortality (from the time of admission).

POLICY AFTER REBLEEDING

Rebleeding was treated either conservatively, by a surgical operation, or by endoscopic injection sclerotherapy (performed by one of the authors) according to the wishes of the admitting clinicians.

\section{STATISTICS}

The Mann-Whitney test was used for analysis of non-parametric quantitative data. Categorical data were analysed by $\chi^{2}$ with Yates's modification when appropriate.

\section{ETHICS}

Informed consent was obtained from each patient or a close relative before endoscopy. Ethical permission for the study was granted by the Ethics of Medical Research Subcommittee for Medicine and Clinical Oncology.

\section{Results}

\section{PATIENTS}

Between January 1989 and March 1990, 184 patients were considered for inclusion into the study. Altogether 109 fulfilled the entry criteria and were randomised to the study. Forty four patients were excluded because they had no endoscopic stigmata of recent haemorrhage, although they had apparently bled from a peptic ulcer, 19 had other causes of bleeding (varices $(n=3)$, gastritis $(n=2)$, carcinoma $(n=3)$, aortoduodenal fistula $(n=2)$, oesophagitis $(n=3)$, Mallory Weiss tear $(n=6)$, no cause $(n=3)$ ), and eight patients had inaccessible ulcers, principally within awkwardly deformed duodenal caps.

Fifty six patients were randomised to injection sclerotherapy and 53 patients were treated conservatively. These two groups were well matched with regard to age, sex, initial haemoglobin concentration, the presence of shock and protuberant vessel. Similar numbers had significant cardiorespiratory disease or had taken nonsteroidal anti-inflammatory drugs; the distribution of duodenal, gastric, and anastomotic ulcers was also similar (Table I).

\section{OUTCOME}

Endoscopic sclerotherapy was performed quickly and easily in most patients. Injection occasionally provoked temporary bleeding in some patients but this rapidly stopped after adrenaline injection. No significant complications were associated with sclerotherapy. Abdominal pain did occur occasionally during the procedure, particularly in patients with anterior duodenal ulcers. Histology after sclerotherapy was available in two patients. In one of these mucosal and submucosal necrosis was present some distance from an injection site; endarteritis was observed in both cases.

The clinical outcome in the two groups of patients is shown in Table II. Seven patients $(12.5 \%)$ treated by injection sclerotherapy rebled compared with 25 patients $(47 \%)$ in the conservatively treated group $(p<0.001)$.

One of the treated group who rebled after initial sclerotherapy underwent further sclerotherapy with adrenaline and ethanolamine. There was no further bleeding and the patient was subsequently discharged from hospital. The remainder underwent urgent surgery and had an uneventful recovery. Nine of the group randomised to conservative therapy who rebled underwent urgent surgery: one patient died after a series of operations for recurrent bleeding and necropsy examination showed extensive destruc- 
tion of the coeliac axis by a benign duodenal ulcer. Two other patients in the conservative group who rebled died from uncontrolled haemorrhage before active therapy could be administered. Fourteen patients who rebled were treated endoscopically. All these patients suffered cardiorespiratory or cerebrovascular disease. Injection sclerotherapy successfully controlled rebleeding in 10 of these subjects. The remainder underwent urgent surgery which was successfully accomplished with no hospital mortality.

There were trends towards fewer operations and lower transfusion requirements in the sclerotherapy treated group (Table II), although these trends did not achieve statistical significance. There were no differences in duration of hospital stay or $\mathbf{3 0}$ day mortality between the groups. Neither the distribution of ulcers (gastric versus duodenal) nor the consumption of non-steroidal anti-inflammatory drugs seemed to affect outcome.

\section{Discussion}

This study has shown that injection sclerotherapy with a combination of dilute adrenaline and ethanolamine reduces rebleeding in high risk peptic ulcer patients. Since rebleeding is the most important risk factor for death from bleeding ulcer, ${ }^{17}$ it is likely that this treatment does improve the prognosis of these patients. The low mortality in this series and the use of injection sclerotherapy after rebleeding in the conservatively treated group are probable reasons for our failure to show any effect upon hospital mortality.

Injection sclerotherapy was performed without acute or long term complications. Perforations did not occur in this (or other ${ }^{11-13}$ ) series and uncontrollable bleeding was not precipitated by the injection. We advocate therapy to the periphery of the bleeding ulcer, aiming to thrombose feeding blood vessels rather than injecting into the middle of a protuberant vessel which in reality is a pseudo-aneurysm of the artery. ${ }^{18}$ Our choice of injection material was based upon the observation that injection of adrenaline stops active bleeding from peptic ulcers, ${ }^{9}$ but we felt that a sclerosant should also be used to prevent rebleeding. ${ }^{19}$ We reasoned that vasoconstriction and haemostasis, effected by adrenaline would localise the sclerosant to the injected area, maximising its effect. Our choice of ethanolamine was based upon experience in sclerotherapy of oesophageal varices and we have no reason to consider it superior to any other sclerosant.

In some patients, endoscopy was performed two to seven days after sclerotherapy and in others it was repeated four to six weeks later.
Rather surprisingly, peptic ulcers seemed to heal as rapidly as anticipated and fresh ulcers did not develop at the injection sites.

The implications of this study for an acute gastrointestinal service may be considerable. We have shown that endoscopic therapy does improve the rebleeding rate of bleeding peptic ulcer and presumably the earlier treatment is given, the better will be the outcome. Consequently, emergency therapeutic endoscopy should be performed as soon as possible after the patient has been resuscitated, balancing the benefits of early haemostasis against the deficiencies of out of hours endoscopy, often with inexperienced assistance and an unfamiliar emergency environment.

We are extremely grateful to all the medical and surgical units at St John's Hospital, Livingston, Eastern General Hospital, Western General and Royal Infirmary of Edinburgh.

1 McLeod IA, Mills PR, Mackenzie JF, Joffe SN, Russell RI Carter DC. Neodynium yttrium aluminium garnet lase photocoagulation for major haemorrhage from peptic ulcers and single vessels: a single blind controlled study. $B M \mathcal{F}$ 1983; 286: 345-48.

2 Swain CP, Kirkham JS, Salmon PR, Brown SG, Northfield TC. Controlled trial of $\mathrm{Nd}$-Yag laser photocoagulation in bleeding peptic ulcers. Lancet 1986; i: 1113-17.

3 Storey DW. Endoscopic control of peptic ulcer haemorrhage using the heater probe. Gut 1983; 24: A967.

4 Shorvon PJ, Leung JW, Cotton PB. Preliminary clinical experience with the heater probe at endoscopy in acute upper gastro-intestinal bleeding. Gastrointest Endosc 1985; 31 $364-6$.

5 O'Brien JD, Days SJ, Burnham WR. Controlled trial of smal bipolar probe in bleeding peptic ulcers. Lancet 1986; $\mathrm{i}$ 464-7.

6 Brearly S, Hawker PC, Dykes PW, Keighley MR. Per endoscopic bipolar diathermy coagulation of visible vessels using a $3 \cdot 2 \mathrm{~mm}$ probe. A randomised clinical trial. Endoscopy 1987; 19: 160-3.

7 Wara P. Endoscopic electrocoagulopathy of major bleeding from peptic ulcer. Acta Chir Scand 1985; 151: 29-35.

8 Laine L. Multipolar electrocoagulation in the treatment of peptic ulcers with bleeding visible vessels. A prospective peptic ulcers with bleeding visible vessels. A prosp
controlled trial. Ann Intern Med 1989; 110: 510-14.

9 Chung SC, Leung JW, Steele RJ, Crofts TJ, Li AK. Endoscopic injection of adrenaline for actively bleeding ulcers; a randomised trial. $B M F$ 1988; 296: 1631-3.

10 Sugawa C, Fugita Y, Ikeda T, Walt AJ. Endoscopic haemostasis of the upper gastro-intestinal tract by local injection of 98\% dehydrated ethanol. Surg Gynae Obstetrics 1986; 162 $159-63$.

11 Wardehoff D, Gros H. Endoscopic haemostasis by injection therapy in high risk patients. Endoscopy 1982; 14: 196-9.

12 Sohendra N, Grimm H, Stenzel M. Injection of non-variceal bleeding lesions of the upper gastro-intestinal tract. Endoscopy 1985; 17: 129-32.

13 Panes J, Viver J, Forne M, Garciaolivares E, Marco C, Garau J. Controlled trial of endoscopic sclerotherapy. Lancet 1987; ii: 1292-4.

14 Foster DN, Miloszewski KJA, Losowsky MS. Stigmata of recent haemorrhage in diagnosis and prognosis of upper gastro-intestinal bleeding. $B M \mathcal{F} 1978$; i: 1173-7.

15 MacLeod IA, Mills PR. Factors identifying the probability of further haemorrhage after acute upper gastro-intestinal haemorrhage. Br ₹ Surg 1982; 69: 256-8.

16 Branicki FJ, Boey J, Fok PJ, Pritchett CJ. Bleeding gastric ulcer: Prospective evaluation of rebleeding and mortality. Aust N Z F Surg 1989; 59: 551-62.

17 Avery-Jones F. Haematemesis and melaena with special reference to causation and the factors influencing mortality from bleeding peptic ulcer. Gastroenterology 1956; 30: 16690.

18 Swain CP, Storey DW, Bown SG, et al. Nature of the bleeding vessel in recurrently bleeding gastric ulcer. Gastroenterology 1986; 90: 595-608.

19 Rutgeerts P, Vantrappen G, Broeckaerts L, Coremans G, Janssens J, Hiele M. Comparison of endoscopic polidoconol injection and Yag laser therapy for bleeding peptic ulcers. Lancet 1989; i: 1164-7. 